\begin{tabular}{|l|l|}
\hline Reimaginação do cinema latino-americano & Titulo \\
\hline Costa, Sebastião Guilherme Albano da - Autor/a; & Autor(es) \\
\hline $\begin{array}{l}\text { De Raíz Diversa. Revista Especializada en Estudios Latinoamericanos (Vol. 1 no. 1 } \\
\text { abr-sep 2014) }\end{array}$ & En: \\
\hline México D.F. & Lugar \\
\hline $\begin{array}{l}\text { Programa de Posgrado en Estudios Latinoamericanos, Universidad Nacional } \\
\text { Autónoma de México }\end{array}$ & Editorial/Editor \\
\hline 2014 & Fecha \\
\hline Cine; Industria cinematográfica; Material audiovisual; América Latina; & Colección \\
\hline Artículo & Temas \\
\hline "http://biblioteca.clacso.edu.ar/Mexico/ppel-unam/20160614025655/Guilherme.pdf" & Tipo de documento \\
\hline $\begin{array}{l}\text { Reconocimiento-No Comercial-Sin Derivadas CC BY-NC-ND } \\
\text { http://creativecommons.org/licenses/by-nc-nd/2.0/deed.es }\end{array}$ & URL \\
\hline
\end{tabular}

Segui buscando en la Red de Bibliotecas Virtuales de CLACSO

http://biblioteca.clacso.edu.ar

Consejo Latinoamericano de Ciencias Sociales (CLACSO)

Conselho Latino-americano de Ciências Sociais (CLACSO)

Latin American Council of Social Sciences (CLACSO)

www.clacso.edu.ar

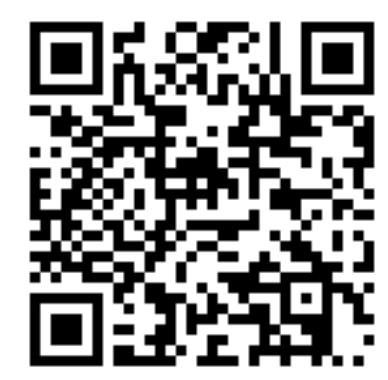




\title{
Reimaginação do cinema latino-americano
}

\author{
Sebastião Guilherme Albano *
}

ReSUMo. Formulamos aqui noções que sinalizam a necessidade de revisão dos enunciados acerca da produção de audiovisual na América Latina. Imagens de consenso, poéticas da responsabilidade, cronotopia (utópica e distópica), entre outras, talvez reconsiderem os esquemas relativos aos modelos de promoção política e econômica do cinema e seu desdobramento estético. Em face da incipente posição que tensiona esses aspectos e relegue o viés meramente local da atividade, como o fazem os estudos do world cinema (inspirado na teoria do sistema-mundo), salientamos, mediante classificação, o desempenho de filmes realizados na região em circunstância de transnacionalização das instituições e da imaginação social.

Palavras-chave: Audiovisual, América Latina, poéticas da responsabilidade, cronotopia.

Resumen. Postulamos aquí una serie de nociones que fungen como una revisión crítica de los enunciados estables que sostienen la actividad del audiovisual en América Latina. Imágenes de consenso, poéticas de la responsabilidad, cronotopía (utópica y distópica), entre otras, reconsideran las proposiciones relativas a los modelos de promoción política y económica del cine y su desdoblamiento estético, en sentido amplio. Debido a la ausencia de una posición que tensione conjuntamente esos aspectos y que aplaque el prisma meramente local de la actividad, un poco lo hacen los estudios del world cinema (basado en la teoría del sistema-mundo), valoramos, mediante clasificación, el desempeño de filmes realizados en la región en una coyuntura de transnacionalización de las instituciones y de la imaginación social.

Palabras clave: Audiovisuales, América Latina, poéticas de la responsabilidad, cronotopía.

ABSTRACT: We seek at formulating some notions that underline the necessity for revising some assertions concerning the audiovisual production in Latin America. Images of consensus, poetics of responsibility, cronotopia (utopian and dystopian), among others, are able to reshape the narrative scheme of the cinema history. Our proposal gathers models from political and economic thought about cinema in order to unfolding at aesthetic issues. Given the lack of a position that stresses these aspects (apart from World-System Theory), we point out, by classification, the performance of films made within the region under the aegis of transnational institutions. We underline that these

* Professor da Universidade Federal do Rio Grande do Norte (UFRN). Atualmente se encontra em estágio pós-doutoral no México e nos Estados Unidos. Tem bolsa da CAPES 
institutions mainly tend to include in their set of arguments the ones concerning to economic and political interests instead the aesthetics ones.

KeYwORDs: Cinema, Latin America, poetics os responsibility, cronotopia.

Recibido: 27 de agosto de 2013. Aceptado: 10 de octubre de 2013.

INTRODUÇÃO

A

Imejamos um exercício de taxonomia que considere as condições de formação de algumas argumentações e suas implicações na imaginação e no que chamaremos pouco certeiramente de sensibilidades (pathos, sensação, afetos, emotividade) predominantes no cinema da América Latina, sendo que o recorte geográfico invoca sentidos que tão somente tangenciaremos aqui, mas que permeia todas as nossas formulação. Tentamos igualmente distanciar-nos das teorias do sistema-mundo (e sua subsidiária do cinema mundo), mas também do aparato pós-estruturalistas, mas estamos conscientes de sua infiltração em nossa mentalidade ensaística. Imagens de consenso e poéticas da responsabilidade são as macronoções axiomáticas que elaboramos com o intuito de dar conta dos estímulos estéticos e sociopolíticos que parecem atuar sobre o audiovisual da região. Esse par de noções pretende operar uma reconsideração de outras lógicas classificatórias, em efeito de mise en abyme, tais como as que fixam as tendências expressivas, de conteúdo, de gêneros e a periodicidade da historiografia do nosso cinema. Seu fim é remoçar o olhar sobre os critérios para que divisem a miríade de intertextualidades e conjunturas políticas e econômicas, mas também se percebam as sensibilidades etc. Uma tal interação corrente no fluxo da vida, quando dispostas em uma discursividade como a do filme para cinema, parece advir em mero dado ético, estético ou comunicativo, separadamente, concretizando-se sempre o que podemos denominar de fetichização ampla (por parecer não passar de um sistema de citações fetiche). Nosso afã é sugerir o contrário por via de uma taxonomia.

Procederemos por mistura e acumulação: às séries maiores trataremos de etiquetar outras tipologias (o vertiginoso mise en abyme) concernentes às condições de uso da noção de cronotopias, em seus perfis utópicos e distópicos, enquadrando-as, na medida do possível, no traçado dos regimes de representação/apresentação, traçado, antecipamos, eles também com desinências taxonômicas. Muito embora já bem contestados, hoje os critérios de análise em 
parte das ciências sociais ainda se orientam por disjuntivas simples (estética/ sociológica, cinema comercial/cinema de arte, Hollywood/world cinema, utopia/pragmatismo, mundo da vida/texto, ficção/realidade, tempo/espaço, entre outras) ou por fases quase estanques, a saber 1) os primórdios, da acepção técnica à descoberta da potência discursiva ligada às artes e ao entretenimento, 2) os intentos de industrialização mais os Cinemas Novos, Nuevos Cines e 3) a Retomada ou os Nuevos Nuevos Cines (Rodríguez, 2012).

Para afiançar as macronoções convém testar um vocabulário específico que logre diluir os limites anteriores e suas consequências classificatórias e rearranjar os sinais de modo a adquirirem sentidos e significados isoladamente e no conjunto, dentro e fora da diégese. Para tanto, reabilitamos o conceito de cronotopia, com seus desdobramentos utópicos e distópicos, e sua incumbência será estabilizar, ou talvez desestabilizar (territorializar/ desterritorializar, codificar/decodificar), as modalidades até então atribuídas aos filmes latino-americanos. Não por outra coisa que uma opção que imaginamos didática passearemos pelos temas e pelos filmes com uma lente metapolítica (Badiou, 2009), aquela que nos permite deslindar os termos decisivos, tingi-los com a coloração do seu tempo e observar como os filmes podem adquirir prismas inesperados.

As noções de imagens de consenso e de poéticas da responsabilidade, e suas renovadas implicações cronotópicas (utópicas/distópicas), visam a provocar as narrativas da crítica, da sociologia e da historiografia do cinema mediante uma denúncia aos modos em que séries fílmicas representam ou mesmo apresentam, nos quadros da figuração ou da plasticidade, modelos de mundo cujo texto e subtexto, o intertexto e o paratexto, o dentro e o fora do campo (contexto?), não apenas aludem aos modos mais influentes de enunciação ou de sensibilidade de seus tempos como estão explicitamente integrados a eles, constituídos por e constituíndo-se como deíticos culturais. Desse modo, o que em algum momento foi considerado utópico pode transformar-se em distópico quando inserido em outro regime de ideias e interesses (desejos, poder etc.), sem menoscabo da complexidade da proposição e com pouca resistência por parte de outras séries de ideias.

\section{IMAGENS DE CONSENSO/POÉTICAS DA RESPONSABILIDADE/CRONOTOPIAS}

Para circunscrever a noção de imagens de consenso ao viés distópico a consignamos ao regime de representação/apresentação de boa parte dos 
filmes do denominado período de industrialização e dos Cinemas Novos, Nuevos Cines. Imagens de consenso assinala a aderência aos modos de produção, bem como aos enunciados e esquemas iconográficos e miméticos hegemônicos do estado nacional (Balibar, 1996) e das teorias das ciências sociais e humanas, mas a rigor os filmes que as desenvolvem não estão cingidos a períodos, mas a modos de figuração. Nesse caso, sugerimos séries de periodicidade alargada, que sacolejem as diretrizes anteriores que uniam apenas as datas com a tipologia produtiva elementar (industrial, de autor) e lhe agregamos ainda o mote da distopia, por seu arranjo do mundo em desconformidade, primeiro alienado e depois alienante, ou vice versa.

Casos exemplares dessas séries são as películas da Revolução Mexicana. Filmes como El prisionero 13 e Vámonos con Pancho Villa (Fernando de Fuentes, 1933 e 1935/36), Flor Silvestre, Enamorada (Emilio “Indio" Fernández, 1942, 1946) capricham na gesticulação nacionalista, dos ícones aos idioletos, e seguem à risca uma cartilha nacionalista que, se bem nem sempre é tematicamente ufanista (como no caso do primeiro filme, que narra criticamente uma pequena atrocidade entre as grandes fatalidades que grassam nas guerras), mantém a cumplicidade iconográfica (Albano, 2011).

Boa parte das obras consideradas nesse rubrica dão a impressão de haver tentado produzir (reproduzir?) aqui os esquemas logísticos e os aspectos discursivos já testados em Hollywood e em cinematografias nacionais europeias importantes, facilitando que se distinga de pronto a divisão internacional do trabalho intelectual e o planejamento econômico (ideológico, para alguns, fruto de agenciamentos, para outros) dessa vertente da colonização do imaginário por um tipo de poder imperial (Sontag, 1999). A constante que congrega certa vertente fílmica tem o intuito de reelaborar nos idiomas e nas tradições locais os sinais nacionalistas exibidos alhures, ressaltando o fenômeno de transnacionalização do nacionalismo discursivo moderno tal como conhecemos no sistema de estados nacionais. Western-revolución; musicais-comedias rancheras-tangadas-chanchadas; cinema soviético-Ozu-neorrealismo-cinemas novos, certamente pertencem a uma corrente comum que abarca sistemas epistemológicos e sensibilidades artísticas, desenvolvimento técnico (avanços nos sistemas de iluminação, conformacão das câmeras etc.) e espírito do tempo. 
Como metáfora ainda, sob a égide de imagens de consenso de prisma distópico, pode-se observar a transferência para o campo cinematográfico, inclusive para a diégese, do esquema de substituição de importações vigente na economia latino-americana. Esse modo de produção/figuração ocorre quase como uma estrutura de funcionamento nessa periodicidade alargada (entre 1930 e 1970?). Como referido, uma de suas peculiaridades internas encontra-se no fato de que nos primeiros vinte anos nos deparamos com gêneros bem marcados, musicais (comédias urbanas ou rurais), dramas (ou melodramas), filmes históricos, adaptações literárias, chanchadas, filmes de cabareteras, capitulado ulteriormente em favor de linguagens documentais, de realismos engajados e em preto e branco ou parafernália pop sob a etiqueta de independente ou marginal (no caso do Brasil), antecedentes do que hoje se conhece como world cinema, uma espécie de tomada de consciência do próprio cinema enquanto organismo vivo que visa a se preservar como discurso social influente.

Imagens de consenso evocam uma vontade romântica no que se refere às tentativas de organizar um sistema de produção (seja industrial em regiões de industrialização insipiente, seja socializado em regiões de tradição patriarcal) e também no que se refere à tentativa de construir um repertório diegético sempre bastante idealizado, com base em trocas simbólicas desiguais, obstaculizando o fluxo de tradições linguísticas e iconográficas que não se aclimatam aos formatos condicionados pelos meios (filme de longa-metragem para cinema e tudo que isso implica) e calcadas em circunstâncias de autoritarismo retórico típicas das relações internacionais entre estados-nação liberais. Essas marcas não estão explícitas em filmes contemporâneos (mesmo com as ubíquas proposições do multiculturalismo e da visibilidade das minorias étnicas, de gênero, de classe, das diásporas etc.), pois o tom de ensaio distópico, enraizado na cronotopia que se imaginava meramente vernacular, foi deixado para trás. Hoje o repertório referencial é de fato cosmopolita, ainda nos cineastas mais locais: Lucrecia Martel, Paz Encina, Cláudio Assis, Lírio Ferreira, Gerado Naranjo, Amat Escalante, entre outros.

Os filmes normalmente inseridos no ciclo dos Cinemas Novos são ainda subdivididos em três apartados pela crítica, que denotam regimes de representação/apresentação peculiares, procedendo um perfil político/ ensaístico de um lado (Historias de la Revolución, Tomás Gutiérrez Alea, 1960; O desafio, Paulo César Saraceni, 1965; Los guerrilleros, Luca Demare, 
1965; La víspera, Alejandro Pelayo, 1982), enquanto se estende outro de teor dramático/realista (Araya, Margot Benacerraf, 1959; O padre e moça, Joaquim Pedro de Andrade, 1965; El camino hacia la muerte del viejo Reales, Gerardo Vallejo, 1971; La pasión según Berenice, Jaime Humberto Hermosillo, 1975), ao mesmo tempo em que vicejam alegorias barrocas (Terra em transe, Glauber Rocha, 1967; Macunaíma, Joaquim Pedro de Andrade, 1969; El castillo de la pureza, Arturo Ripstein, 1972; La última cena, Tomás Gutiérrez Alea, 1976) ao menos nos filmes produzidos até mais ou menos 1975. Registramos essa partição, mas não a levamos muito a sério uma vez que está embasada em um certo arranjo cujos consensos que o promovem são os mesmos que estabelecem hierarquias, axiologias, que determinam tanto as normas como as exceções.

Por seu turno, o termo poética da responsabilidade não reivindica uma ruptura com tais parâmetros e até insinua uma convivência cuja marca é uma atualização da problemática ao incorporar na reflexão a complexa rede de financiamento engendrada depois do Consenso de Washington, que tudo determina nos contornos estéticos e éticos da produção cultural institucionalizada, inclusive os modelos de incorporação das proposições consagradas pelas epistemes acadêmicas nos últimos 30 anos. A partir de então, muito embora não haja ocorrido um distanciamento completo do apoio dos estados nacionais em alguns países (bastante sólido nos anos entre 1950 e 1989), manobraram-se os termos jurídicos para que houvesse uma concentração do incentivo ao setor cinematográfico em parcerias público-privadas, encarnadas em coproduções ou submetidas a editais de instituições que promovem festivais de cinema e são o bastião cultural desse estágio do capitalismo. E esse detalhe jurídico-logístico foi decisivo. Expressão estética da capciosa lógica do politicamente correto contemporâneo, sua consequência foi desobrigar as novas gerações do gosto ou do dever representar/apresentar os estados nacionais por intermédio do nacionalismo e as doutrinou na língua franca dos festivais, o grande sujeito da enunciação de um certo tipo de filme que em termos gerais se pode incluir no chamado world cinema.

Dessa maneira, pela temeridade de se pensar uma teoria do audiovisual, propriamente do cinema, sem nos reportarmos a uma teoria do cinema como produção social, ideou-se denominar o resultado das forças políticas e econômicas nos quadros estéticos dos filmes regionais principalmente a partir de 1990 com uma corruptela provinda das categorias 
cunhadas por Max Weber e inspiradas em sua teoria sobre a atuação dos líderes em sociedades complexas, agregado de um inusitado marco utópico, uma nova flexão para os regimes de representação/apresentação recentemente disponíveis (Weber, 1982). Não é excessivo remarcar que ética da responsabilidade e ética da convicção reportam-se a um agente político que deveria ser levado a tomar decisões motivadas, no caso da segunda hipótese, por uma atitude ética relativa aos valores ou convicções. Já no caso da primeira, deveria mirar a eficácia e eficiência dos meios para alcançar seus fins, circunscritos a conjunturas e interesses episódicos.

Adaptamos com algum reparo os lineamentos da ética da responsabilidade a fim de sustentar nossa tese a respeito da impressão mais consistente que se tem dos resultados da racionalização excessiva da atividade cinematográfica contemporânea na América Latina a partir do Consenso de Washington, cujo corolário foi o conceito de poética da responsabilidade. Essa ponderação mercadológica que os atores envolvidos no processo de concepção de um filme adotam e o aspecto burocraticamente globalizado de sua concreção (o fator utópico, desnacionalizado) estão patentes em filmes como Miroslava (Alejandro Pelayo, 1993), Sexo, pudor y lágrimas (Antonio Serrano, 1999), Nueve reynas (Fabián Bielinsky, 2001), Vereda tropical (Javier Torre, 2004), Se eu fosse você (Daniel Filho, 2006), Morirse en domingo (Daniel Gruener, 2006), Kilómetro 31 (Rigoberto Castañeda, 2006), Divã (José Alvarenga Filho, 2009) e em menor escala porque independentes ou de cinematografias insipientes, mas com um regime de representação/apresentação infantilizado ou ambicioso, La virgen de los sicarios (Barbet Shroeder, 1999), Zona Sur (Juan Carlos Valdivia, 2009), Hermano (Marcel Rasquin, 2010), El cártel de los sapos (Carlos Moreno, 2011), e 7 cajas (Juan Carlos Maneglia e Tana Schémbori, 2012), entre muitos outros.

\section{MISE EN ABYME/AXIOLOGIA/TAXONOMIA}

O desdobramento do elemento cronotópico e seu tergiversamento possibilita afinar a inteligibilidade deste estudo. As linguagens que o cinema desenvolve inscrevem dimensões representativas e presentativas (e tantas outras combinações) ao mesmo tempo em que incluem a expressão cinematográfica em um formato social que valoriza a narrativa (pathos, verossimilhança, mimese, espaço/tempo, alcances afetivos pré-determinados). 
Para desafiar as certezas, ativamos suas variantes distópicas e utópicas e lhes atribuímos um novo emprego nos filmes da região, situação que altera verdades erigidas pelos experts coaguladas no senso comum, inclusive acerca da inclusão ou exclusão do sujeito nacional, do sujeito colonial, do sujeito pós-colonial, do sujeito moderno, do sujeito pós-moderno no quadro de representação/apresentação. Em linhas gerais, tomamos a noção de cronotopia por referir-se à concorrência de indícios do mundo da vida (temporais e espaciais-históricos e geopolíticos) ou de outros modelos de discursividade nos meandros da diégese literária e fílmica a fim de gerar um tipo específico de verossimilhança que parece encerrar elementos de dentro e de fora do campo da imagem cinematográfica, um modelo de imagem inorgânica (Bakhtin, 1988; Guattari y Deleuze, 1995). Cronotopia em suas variantes distópicas e utópicas poderia sugerir rearranjos mais depurados para um conjunto de filmes produzidos em condições um pouco semelhantes.

Antes de prosseguir, restam dois dados a esclarecer. Primeiro, subentende-se que lidamos com obras com um teor realista, noção que não problematizaremos aqui, mas que supõe um arranjo dos materiais fílmicos segundo postulados representativos/apresentativos. Segundo, quando nos remetemos a filmes anteriores a 1990, em geral estamos nos referindo a produções argentinas, brasileiras ou mexicanas, uma vez que aí se produziram cerca de 90 por cento das películas da região até então. Os motivos para a pouca ou nenhuma produção no restante dos países da América Latina revela tanto das circunstâncias históricas da região como aquele convidado de honra que brilha por sua ausência.

Como referido, a acepção de utopia e mesmo de distopia a que nos remetemos talvez destoe do seu emprego moderno e contemporâneo, mas se justifica pela evocação à etimologia dos termos e pela aderência ao fenômeno da cronotopia, figura vinculada à mimese e à verossimilhança correntes no audiovisual latino-americano. Ao invés de concebermos utopia como um projeto quimérico, idealista ou romântico apenas, prenhe do princípio esperança almejado por Ernest Bloch no século XIX e muito menos com a leitura utópica que hoje se sugere do inca Guamán Poma Ayala, que já no século XVII no vice-reino do Peru ideou um panorama burocrático para el buen gobierno (Dussel; Mendieta; Bohórquez, 2009), empregamo-lo diretamente para aquele modo de representação/ apresentação fílmica que abstrai a imagem, o som e o movimento da re- 
ferencialidade mais ostensiva ao mundo já significado do lado de fora da diegese (até porque em nosso entendimento quase todos os elementos de um filme podem ter sentido, talvez todos).

Utopia para nós aqui evoca a indeterminação da referência cronotópica e configura assim uma espécie de não lugar ou de lugar inaugural, porquanto seu plano cronotópico é difuso e não segue a norma da imagem como reflexo ou analogia do real físico, mas como uma vitualidade. La invención de Cronos (Guillermo del Toro, 1992), Silvia Prieto (Martín Rejtman, 1999), La libertad (Lisandro Alonso, 2001) e Alegria (Felipe Bragança e Marina Meliande, 2010) se reportam a essa categoria, vinculada então à promessa discursiva de criar mundos verossímeis sem o recurso aos lugares comuns, o que inclui o mobiliário nacionalista convencional. Tal característica é responsável pelos resultados estético-políticos dos filmes de diretores nascidos a partir dos anos 1960 na América Latina como Carlos Reygadas, Martín Rejtman, Lisandro Alonso, Julio Hernández Cordón, Claudia Llosa, Guillermo del Toro, Cláudio Assis, Kleber Mendonça Filho, Gerardo Naranjo.

A ideia de utopia, da imagem como uma virtualidade, pode ser atribuída a muitos filmes relativos às poéticas da responsabilidade, mas encontramos uma feliz culminância em um curta de Carlos Reygadas intitulado Este es mi reino, que compõe a peça coletiva Revolución, 2010. Encenando um documentário familiar, quase em primeira pessoa devido ao efeito da câmera ao ombro em boa parte do tempo, o filme relata/representa/apresenta uma reunião de pessoas com um idioma comum em uma espécie de festim dionisíaco ao ar livre e em uma paisagem que remete ao campo mexicano, mais precisamente a Tepoztlán, no estado de Morelos (lugar em que o diretor do filme tem casa), palco de importantes embates liderados por Emiliano Zapata durante os anos de guerra civil no México, entre 1910 e 1917. No segundo plano do filme, um homem de tipo mediterrânico, vestido de guayabera branca, chapéu panamá e óculos escuros conversa com uma mulher de tipo latino-americano burguês, morena clara, com óculos escuros da moda e expressão interessada no que ele dizia acerca de ser aquela mesma paisagem que estão vendo, com as montanhas ao longe e a proximidade do Cerro del Tepozteco, a mesma que divisou Hernán Cortés quando chegara do que hoje é o estado de Veracruz e granjeou apoio entre as sociedades locais, inimigas dos astecas, a quem conquistariam quando arribassem à Cidade do México, D. F. 
A partir daí, o ritmo da câmera, os planos e os cortes começam a ser mais breves, rápidos e instáveis, acompanhando a chegada de uma variadíssima tipologia de convidados que em pouco tempo estão bêbados, montando a cavalo, destruindo um automóvel, orinando, discutindo. Essas marcas, esse temperamento explosivo do filme são consoantes ao retrato que fez Mariano Azuela em Las moscas (1918) e Martín Luis Guzmán em La sombra del caudillo (1928) dos eventos da Revolución. Se formos contabilizar, as referências literárias são muito mais numerosas no filme de Reygadas do que as cinematográficas, muito embora haja eco das ideias fílmicas de Fernando de Fuentes. E o que foi considerado à época em seus filmes de inícios de 1930 como posições críticas ao evento e às vezes, a depender do espectador, até reacionárias, hoje são politicamente corretas. Tanto no filme de 2010, como nas películas de Fernando de Fuentes ou nos romances supracitados, o que predomina é a sensação de caos, os signos do descontrole a causarem medo, a desrazão. Não falamos em influência, mas talvez intertextualiades e consonância anímica entre as imagens (verbais, sonoras, visuais), muito embora haja fluxos e influxos de um padrão afetivo. Também os escritos cristãos parecem alimentar o filme, talvez os mesmos livros da Bíblia, que se incorporam ao nome do filme, Este es mi reino, mais ainda se considerarmos a transformação ocorrida em nosso estado de espírito entre as bucólicas imagens iniciais de uma mula imóvel e as funestas chamas apresentadas no encerramento da película enquanto aparece o título. É notável como a mística judeu-cristã percorre a obra de Reygadas.

A multiplicidade de subtextos atualizados impossibilita uma posição representativa muito clara, anulando ainda qualquer tentativa de interpretação ideológica do filme. Sua disposição dos materiais dramáticos, plásticos, narrativos e líricos quase obstaculizam a possibilidade de se pensar no filme como um comentário da Revolución, quase. O desdobramento ético, comportamental, psicossocial exaustivamente prescrutado pelas epistemes e pelo senso comum no que concerne aos legados da guerra e os indicativos de classe que encerram a tonalidade da pele e o comportamento dos personagens do filme, tão presentes nas representações clássicas da Revolução e que compõem de fato a sociedade mexicana, quando invocam a cronotopia pintoresca o fazem de maneira difusa, relativizando a coordenada geográfica e colocando o que se passa naquele mundo dentro de várias tradições discursivas, equiparando história, vida, sensibilidades, opinião. 
O filme O som ao redor (Kleber Mendonça Filho, 2012) promete resultados semelhantes, sendo que paranóia e vingança são os motes mais evidentes na psicossomatização dos personagens. Mas a evocação cronotópica cuja leitura referencial em relação ao próprio Recife e à história de Pernambuco (incessantemente declarados pela crítica e pelo próprio diretor) somente consegue ser virtualizada, desmaterializada nos esquemas técnicos e poéticos que permeiam sua performance expressiva até passada a metade do filme. Nas sequências finais, malgrado as alusões a diversas tradições fílmicas (tenho em mente a onda de terror oriental, ou algo como Old Boy, Park Chan-Wook, 2003, ou o posterior Pietá, etc.), explicita-se a duvidosa simpatia, talvez inconsciente, com os filmes ensaísticos latino-americanos.

O pensamento utópico de viés idealista orça uma extensa genealogia, talvez desde o Platão de $A$ república. No eixo Europa-América colonial alcançou um notável desempenho (das missões jesuíticas até Brasília, da obra de Simón Rodríguez até Darcy Ribeiro, do barroco de Góngora até José Lezama Lima e João Ubaldo Ribeiro), chegando a nossos dias, talvez, processado em denominações como hibridização, entrelugar, pensamento de fronteira etc. Essa variação quiçá tenha sido legada, inconscientemente, por autores socialistas (ou anarquistas) como Ernest Bloch e sua teoria dos entremundos (1977). Mas o primeiro registro do termo utopia parece haver sido mesmo na obra homônima de Thomas More, 1516, sendo o texto de Bloch um dos seus corolários nas áreas da filosofia e da política. A Utopia de More inclusive suscitou o florescimento de um gênero literário. Para Karl Otto Apel (1986) por exemplo, tais obras literárias pertencentes ao gênero utópico costumam representar um antimundo hipotético. É precisamente esse fragmento da sua classificação que nos interessa, uma vez que o autor, antes de indicar esse aspecto hipotético ou imaginativo do termo utopia, prossegue na definição por uma acepção mais normativa.

Essa vertente que creditamos ser intuída pelos diretores nascidos a partir de 1960 na América Latina levou-os a adotarem a elipse como tropo importante, uma vez que permite não insistir em esclarecer o que já é significado fora do filme, e cujos resultados narrativos geram novos tropos (anáforas, catáforas, catacreses, sinédoques, alusões, oxímoros etc., como ocorre em Este es mi reino, por exemplo). A grande marca dos filmes encerrados na poética da responsabilidade e de vertente utópica não está apenas na desmaterialização/materialização do nacional, ou melhor 
deslocalização/relocalização das histórias, das locações e das formas de expressão, desnacionalizadas no sentido ostensivo e instrumental do termo. Nas obras há um recorte cosmopolita em que o factual se apresenta como a referencialidade simbólica mundializada, sem âncoras fortes ou raízes locais, a despeito de aludirem a certos arquétipos dos processos civilizadores da região (La teta asustada, Claudia Llosa, 2009; Porfirio, Alejandro Landes, 2011).

Outras constantes se apresentam, como a evocação da natureza (selvas, bosques, mares, montanhas, pradeiras) e seu valor significante (em que cabem alegorias da redenção, da magia, do processo econômico etc.), sugerindo um gosto pelo lugar e pelo local (cidades pequenas, desoladas), sempre e quando se puder demonstrar a renovação dessas marcas românticas (A ostra e o vento, Walter Lima Jr. 1997; La ciénaga, Lucrecia Martel, 2001; La libertad, Lisandro Alonso, 2001; La hamaca paraguaya, Paz Encina, 2006; Agua fría del mar, Paz Fábrega, 2010; Entre el día y la noche, Bernardo Arellano, 2011; Eu receberia as piores notícias dos seus lindos labios, Beto Brant, 2011; Post Tenebras Lux, Carlos Reygadas, 2012; El premio, Paula Markovitch, 2011; Heli, Amat Escalante, 2013). A novidade está em que as florestas tropicais, as selvas verdes e úmidas convivem com as planícies cinzas, às vezes invernais, bem como as motos e as bicicletas agora circulam por entre os carros e aviões de sempre. Por certo, os deslocamentos, as viagens, são parte desse sistema poético contemporâneo.

Esses traços estilísticos são compartilhados com cinematografias de regiões da Ásia, da África e da Europa (Tailândia, Vietnam, Romênia, Tunísia, Turquia) talvez coincidentemente com processos semelhantes de constituição de cinematografias nacionais, com problemas de urbanização agressiva, de racionalização da vida social e com aparência de estar em vias de homogeneização de certos hábitos (talvez tudo o que significa Goodbye South, Goodbye, Hsiao-Hsien Hou, 1996, um marco nesse sentido). Nos filmes citadinos, por seu lado, os efeitos na direção de arte são notáveis, havendo a predominância de dois sistemas, um a inspirar-se no grau zero naturalista (Octubre, Daniel Vega Vidal, 2010; La mujer sin cabeza, Lucrecia Martel, 2008; La vida útil, Federico Veiroj, 2010) e o outro no que se conhece como pop (Sólo con tu pareja, Alfonso Cuarón, 1991; O cheiro do ralo, Heitor Dhalia, 2006; No, Pablo Larraín, 2011), mas em todo caso caudatária de uma iconografia plástica, literária, fílmica, publicitária, inorgânica, fazendo que tudo ali pareça ser mesmo um simulacro, fomen- 
tando o estranhamento. Em locações ou estúdios, urbanos ou campestres, anônimos ou ubíquos, essa combinação promove indefectivelmente a ocorrência de um mundo intermediário. Esse modo de contar/mostrar hoje parece obedecer a um código normatizado pelo sistema dos festivais.

De outro lado, o viés distópico tange precisamente àqueles filmes com lastro em tradições nacionalistas, regionalistas, de ordinário de contornos ensaísticos, que estão em desacordo moral com o mundo representado ou com os enunciados epistêmicos e sociais acerca do núcleo temático do filme, e como consequência esse aponta para uma realidade extrafílmica igualmente rarefeita. Lançamos mão da categoria para indicar o desconforto apresentado na diégese pelo mundo representado/apresentado, sendo que esse mesmo mundo se manifesta como uma extensão dos conteúdos do mundo social.

As utopias negativas ou as antiutopias, também referidas por Appel, são aqui consideradas apenas como distopias, mas se observam pequenas variações entre suas ressonâncias na literatura e no cinema. Nos contos, novelas e romances de Jonathan Swift, Aldus Huxley, George Orwell, alguns textos de Jorge Luis Borges e Felisberto Hernandez, por comentar alguns, nos quadros de representação/apresentação plasmam-se mundos desfavoráveis, opressivos, os quais os personagens desejam modificar ou não. Ainda que sejam obras alegóricas, escritas por seus autores em circunstâncias sociais críticas, a imaginação se sobrepõe à cronotopia social ou até mesmo à intertextualidade, malgrado esse último elemento não seja uma regra. Se fôssemos utilizar os mesmos postulados lhes arrogaríamos a definição de utópicas, uma vez que desmaterializam o cronotopos social e recriam as coordenadas referenciais. Com uma estratégia de projeção de mundos que reputamos semelhantes aos dessa literatura estão filmes como La invención de Cronos (Guillermo del Toro, 1992), Los guantes mágicos (Martín Rejtman, 2003), Filmefobia (Kiko Goifman, 2008), aqueles que já etiquetamos com o epíteto de utopia.

Em certo cinema regional do período de 1960 (Historias de la Revolución, Tomás Gutiérrez Alea, 1960; Los inundados, Fernando Birri, 1961; Os fuzis, Ruy Guerra, 1964; O desafio, Paulo César Saraceni, 1965) se escamoteiam elementos discretamente alegóricos operando uma espécie de reflexão teórica ou mesmo jornalística, mais que insinuando sua metalinguagem em relação aos conteúdos da sociedade e às epistemes, especialmente as ciências sociais. Ao invés de uma imaginação criadora 
que leva seu gênio à composição de mundos possíveis, tal como faziam há muito os escritores, os diretores (Glauber Rocha, Fernando Solanas, Felipe Cazals, Jorge Isaacs, Alejandro Pelayo, Jorge Sanjinés etc.) exprimiam o dissabor seguido de uma denúncia corrente nas ciências sociais do período, empenhando-se em refletir a circunstância nefasta por que passava a região (ditaduras, guerras civis, miséria, caos institucional) associando-se a uma espécie de movimento internacional de revolta, com o que confluiam. Simplificando, projetavam nosso subdesenvolvimento no cinema sancionando a partilha difundida nas relações internacionais entre primeiro, segundo e terceiro mundos, criando mesmo manifestos político-estéticos, entre os quais Por un cine nacional, realista y popular (Fernando Birri, 1962), Eztétyka da fome (Glauber Rocha, 1965), Hacia un tercer cine (Fernando Solanas e Octavio Getino, 1969), e Problemas de la forma y del contenido en el cine revolucionario (Jorge Sanjinés, 1978).

Ainda assim, tanto nas obras literárias como nas fílmicas de cunho distópico, as bases materiais da vontade de mudança são tangíveis nos conteúdos sugeridos fora do campo e da diégese, sinalizando para o leitor ou espectador, no ato da fruição, traços para a identificação de referências mais ou menos claras no mundo físico ou histórico, que parece desejar-se mudar. Mas à diferença dos textos escritos, os filmes aos que neste trabalho imprimimos o epíteto de distópicos não se conformam como meramente alegóricos e nem visam à constituição de um novo mundo. Seu ponto de vista é tão somente crítico e seu discurso se reporta à economia argumentativa do ensaio nacionalista, trazendo para a superfície diegética apenas uma inconformidade com a conjuntura social de fora da diégese, sem desenhar alternativas.

Duas novas formações taxonômicas poderiam ser sugeridas. A primeira, sob a rubrica de "Ideias fixas e imaginação motora: história, memória e trauma" visa a readaptar as normas acerca de filmes do gênero histórico para outro de cunho memorialístico, em que um personagem quase em primeira pessoa se encarregue de disponibilizar a informação necessária para o conhecimento do conteúdo que se deseja resgatar, em uma encenação de um sujeito fraturado em busca da cicatrização. A segunda, "Sentido comum: transensibilidades, agenciamentos e renovação do sujeito".

A primeira vinculada ao que em outros estudos atribuímos o epíteto de cinema ensaístico (Corrigan, 2011) e o outro tributário de um afã de cosmopolitismo, um cinema urbano ou com aspirações de transcendência 
da realidade idiomática e cultural de sua produção. No primeiro caso, a expensas de não ser mais possível atribuir o estado de coisas contemporâneo como resultante de um conluio imperialista para o esquecimento coletivo, pode-se aventar a ideia da naturalização na maior parte dos autores e nas audiências regionais de uma visualidade pré-fabricada como ocorre em $O$ que é isso companheiro (Bruno Barreto, 1997), Dois córregos (Carlos Reichenbach, 1999), Machuca (Andrés Wood, 2004), Los Andes no creen em Diós (Antonio Eguino, 2007 ), Paisito (Ana Díez, 2008), Pachito Rex (Fabián Hofman, 2008), entre outros. Com a mesma temática e sob a mesma rubrica indicada acima, concorrem com esses filmes Que bom te ver viva, (Lúcia Murat, 1989), Los rubios (Albertina Carri, 2003), Garage Olimpo (Marco Bechis, 2006), Diário de uma busca (Flávia Castro, 2010), Sibila (Teresa Arredondo, 2011), No (Pablo Larraín, 2012), entre outros. A grande diferença corresponde a que se na primeira série manifesta-se aquele fenômeno indicado por Susan Sontag quando aventava a possibilidade de uma imagem-mundo (1999) controlada em suas dimensões formais e até morais, na segunda os filmes elencados indicam a urgência de dar sentido ao passado mediante novas táticas de semiose em um lance de crítica da memória que visa a tergiversar as versões oficiais (Richard, 2010), tanto da história quanto do espaço, muito embora sem nostalgia pelo nacionalismo nem avidez pelos signos da contemporaneidade ostensiva.

$\mathrm{Na}$ outra categorização geral, "Sentido comum: transensibilidades e renovação do sujeito", alinhamos filmes que desde os anos 1980 se habilitam para representar ou, em chave de simulacro, apresentar os traços da vontade pós-moderna de renovação ou dee anulacao do sujeito, uma vez que campeiam motivos do multiculturalismo, da globalização, do novo politicamente correto (acrescido dos valores da esquerda puxados pela direita). Os exemplos iniciais foram realizados ainda sob os limites institucionais do Estado autoritário ou lidando com seus resíduos sem esboçar alusão à circunstância, como Cidade oculta (Chico Botelho, 1986), A dama do cine Shanghai (Guilherme de Almeida Prado, 1988), Hombre mirando al Sudeste (Eliseo Subiela, 1986), Rapado (Martin Rejtman, 1991), Lola (María Novaro, 1989), Cronos (Guillermo del Toro, 1993).

Mas esse último conjunto consolida-se de fato a partir dos anos 2000, com a ascensão de um quadro expressivo atravessado mormente por signos cuja remissão não é mais caudatária da história dos discursos representativos como a literatura popular ou o cinema, ou mesmo tão so- 
mente de um recorte dos simulacros promovidos pelos próprios meios, mas invoca uma nova materialização dos signos de referências espaciais e temporais filtrada pelas soluções auspiciadas pela cultura pop, como em Bolivia (Israel Adrián Caetano, 2001), Los guantes mágicos (Martín Rejtman, 2003), Batalla en el cielo (Carlos Reygadas, 2004), Whisky (Pablo Stoll e Juan Pablo Rebella, 2004), Madeinusa (Claudia Llosa, 2005), Las hamaca paraguaya (Paz Encina, 2006), La mujer sin cabeza (Lucrecia Martel, 2008), Año bisiesto (Michael Rowe, 2010), Viajo porque preciso volto porque te amo (Marcelo Gómez e Karin Aïnuz, 2009), Os famosos e os duendes da morte (Esmir Filho, 2009), La marimbas del infierno (Julio Hernández Cordón, 2010), Alegria (Felipe Bragança e Marina Meliande, 2010), A febre do rato (Cláudio Assis, 2011), El último Elvis (Armando Bo, 2012), O som ao redor (Kleber Mendonca Filho, 2012), Polvo (Julio Hernández Cordon), entre outros.

\section{CONSIDERAÇÕES FINAIS E COMENTÁRIOS GEOPOLÍTICOS}

Essa inversão da interpretação dos termos utopia e distopia, entre outros (memoria, sujeito etc.) aplicada ao cinema latino-americano está imbuída de uma energia de reconsideração dos critérios mais enraizados das axiomáticas correntes e da análise da representação/apresentação fílmica regional. Essa intenção renovadora visa a provocar os estatutos das teorias e críticas contemporâneas, que parecem estar estranhamente livres dentro de uma gaiola, um codigo rigido promovido pelas condicoes do mercado globalizado ou pelas instituicoes de fomento condicionadas pela filosofia do politicamente correto. A miríade de posições e de grupos sociais representados pela academia anuvia as tentativas de se considerar um escopo amplo, como o que nos propusemos aqui. Por isso, nossa tática foi a do acúmulo, da sopreposição, do excesso, resgatando categorias, reacomodando outras, tratando de controlar as intertextualidades (mise en abyme) e gerando novas listas taxonômicas.

Tratamos de lançar luz a novos, posssiveis e paradoxais parâmetros estéticos e sociopolíticos mediante um vocabulário atualizado que remeta mais ou menos a aspectos da tradição fílmica (cinematográfica), mas norteie o traçado de linhas de pensamento acerca do processo de transformação do setor ocorrido a partir do Consenso de Washington (Yudice, 2002). Para tanto, a terminologia convoca fenômenos que estão além das 
periodizações históricas cristalizadas e, ademais, tangenciam a complexidade do campo do audiovisual na contemporaneidade. Noções como poética da responsabilidade, imagens de consenso, world cinema, cinema globalizado, cinema transnacional, tradição iconográfica, crise da linguagem e da mimese, utopia, distopia, heterotopia etc. devem ser trazidas à baila e filtradas por sua atuação no regime de representação (mimese, projeção, métodos de formação de imagens e seus critérios de apresentação e valoração estética e moral etc.). Com a habitual naturalização de projetos progressistas pelos enunciados das instituições mais conservadoras, convém uma recapitulação do vocabulário que tangencia os esforços mais autênticos de nomeação das diferenças, das subalternidades, das discrepâncias materiais e das transformações dos discursos.

A proposta de fundo é, então, relativizar certezas politicamente corretas a respeito de uma reforma no paradigma das relações internacionais lato sensu em que se esboça uma condição de igualdade entre partes cujas relações foram historicamente desequilibradas, mais ainda no âmbito da cultura. Para tanto, insistimos em que, não obstante viceje a ideologia de um mundo multipolar, ainda à semelhança do sistema de substituição de importações de decênios atrás, as políticas para o setor e mesmo a imaginação projetada pelo cinema produzido na América Latina mantiveram e mantêm uma visão algo reflexiva em relação às cinematografias de certas regiões, notadamente no tocante à dramaturgia e às séries iconográficas selecionadas para o modelo de mundo plasmado nos filmes. Mas a despeito de sua recalcada aparência de subalternação, ao se tratar de discursos de natureza dúbia (poética e comunicativa - estética e industrial) a situação reveste-se de um matiz de paradoxo. Tanto mais quando nos propomos a examinar e comentar grupos de filmes a partir de sua inscrição geopolítica mediante um crivo ao que denominamos estético, uma combinação em declínio.

Notadamente depois da adoção do Consenso de Washington a circunstância não escapou a ser assimilada de maneira mecânica pelos saberes acadêmicos resultando na entrada em cena de novos aparatos conceituais franqueados pelas teorias do cinema nos últimos 30 anos (Stam, 2000; Ramos, 2005; Nagib, 2005) quase que para azeitar a máquina explicativa dos Estudos Culturais. Países sem tradição audiovisual institucionalizada como a Costa Rica (Agua fría del mar, Paz Fábrega, 2009) e o Equador (Pescador, Sebastián Cordero, 2011) veem seus filmes ser exibidos e pre- 
miados em festivais internacionais ao mesmo tempo em que se radicaliza uma espécie de sujeição à qual estão expostas as condições materiais e, quase como consequência, a verossimilhança fílmica na região. Cresce o assombro quando se lhe confere invariavelmente o predicado de múltipla a uma cinematografia que, mesmo em seu amplo conjunto (Shaw, 2007), está em tudo limitada, malgrado se saiba que à primeira vista não haja equívoco em afirmar o contrário.

Inclusive se nos munirmos dos argumentos acerca de que a América Latina tem uma larga tradição visual tanto de matriz autóctone e cristã como advindo da relação dessas fontes com os sinais da contemporaneidade, não demoramos a concluir que, na medida do possível, a genealogia das imagens e dos aspectos relativos aos estatutos formais do cinema está para além dessa história meio determinada geograficamente, e se constituiu em um sistema com características semi-autônomas cuja descrição implica percorrer caminhos à primeira vista díspares. Tencionamos, de alguma maneira, comparar a complexidade e definir constantes nas formações discursivas atuais, mas sabemos que talvez chegams apenas a levantar alguns pontos que possam ilustrar nossa ideia da conjuntura da produção de cinema no continente.

Muitas das impressões inscritas acima permeiam os estudos dos cientistas sociais há tempos na América Latina e fora dela mas agora parecem ensejar uma reforma do instrumental teórico que opere em uma dimensão cada vez mais abstrata e combinatória para tratar de dar conta de seus propósitos, como esboçamos anteriormente. Portanto, não se deve descurar em princípio os resultados obtidos por equipes de diretores, fotógrafos, montadores etc., de regiões que passaram por processo civilizatório com alguma semelhança ao da América Latina e o rearticularam discursivamente de outro modo, especialmente quando relativizam a questão nacional de superfície, como ocorreu com toda uma geração de cineastas do Irã e imediações, mas sobretudo com artistas do sudeste asiático, Coréia e territórios da China não continental, cujo mote de representação, ainda que cronotópico, é permeado pelo que Silviano Santiago denomina de cosmopolitismo do pobre (2004). Colonizados por diversos países europeus e depois de 1945 debruçados sobre o dilema de narrar a condição pós-colonial no horizonte da Guerra Fria, um assunto que em sua feição teórica foi muito desenvolvido pelos escritores do Caribe, do Oriente Médio, da Índia e do Paquistão, aqueles extremo-orientais talvez tenham estado mais 
à vontade para comentar o contexto pós-colonial em chave estética, vide o boom de seus artistas, de escritores a performáticos, devido mesmo a especificidades culturais acrescidas de sua peculiar trajetória de inserção capitalista e dos movimentos migratórios do qual participaram e ainda participam.

Por seu turno, cumpre recordar que as instâncias que ao mesmo tempo que criam tendem a avalizar essas dimensões da expressão participam do chamado concerto internacional e dentre suas atribuições está a valoração das ideias, práticas, agenciamentos e conteúdos sociais em geral e das artes em particular. Se eventualmente nos assombram noções como geopolítica cultural e divisão internacional do trabalho, atualíssimas conquanto cada vez mais esvaziadas como articuladora dos sentidos, se contemplarmos os relatos das rusgas entre departamentos de humanidades e especialmente de literatura na academia ocidental nos últimos cinquenta anos, conferimos-lhe um novo crédito. E se percebermos que os vários membros do que se convencionou denominar a diáspora pós-colonial encontraram um locus de onde falar ao mundo, tal como Aimé Césaire, Frantz Fanon, Stuart Hall, Edward Said (Kenway \& Fahey, 2009; Spivak, 2010), que não propriamente seu lugar de origem, nascimento ou criação, tangenciamos a complexidade da globalização, da mundialização e da cosmopolitização. Acima de tudo porque nos interessa, lançamos nova mirada à conjuntura do audiovisual na América Latina para nos instalarmos de pronto na situação já referida como paradoxal. Algo parece haver mudado na relação de forças políticas e epistemológicas que moldam nossa percepção da tradição cinematográfica ao mesmo tempo em que algo parece estar onde sempre esteve.

Recentemente houve uma diversificação e internacionalização da disponibilidade técnica e de financiamento na área do audiovisual, expedientes que muitos Estados latino-americanos não puderam encarregarse de administrar devido a uma falência logística logo após alguns decênios de guerras civis, ditaduras conservadoras e ofensiva neoliberal predatória, mas essa diversificação e internacionalização deu-se em concorrência com um enquadramento ético e estético. Esse, à diferença dos países e enclaves do sudeste asiático recém-colonizados por ingleses e franceses mas sem a adoção plena de seus idiomas, reportou-se tão somente a um campo de influências norte-americano que doutrinou severamente os territórios mais débeis do continente (América Central, parte 
do Caribe e do norte da América do Sul) e pavimentou, com seu agressivo modelo de distribuição e exibição, a formação dos hoje realizadores de filmes na fruição de um imaginário propagado pela ostensiva indústria cultural internacional, capitaneada pelas lógicas de Hollywood ainda que, certamente, em muito hibridizadas e, como referido, dialogando com as epistemes que prometem dar voz aos subalternos. Dentre outras coisas, germinou nesse estado de coisas uma poética que no campo do fabrico de imagens e ainda mais imagens para cinema enseja proporcionar arranjos inesperados. Se às vezes trabalhamos com a metáfora da substituição de importações no caso da recente retomada da produção de países como a Argentina, o Brasil e o México, se mudarmos o foco para o cinema da América Central e o Caribe o tropo também deve ser outro, já que ali ocorre uma produção de cunho institucional incipiente que repercute na forja de um regime de representação que leva a que participe, quase que por antonomásia, dos novos esquemas dos novos players internacionais, isto é, aqueles que se erigem como uma alternativa viável para o sistema dos estúdios de Hollywood e financiam filmes do mundo para serem exibidos sobretudo em festivais, que se proliferaram exponencialmente.

\section{REFERÊNCIAS}

ALBANO, S. G. (2011); A imaginação revolucionária. Política, cinema e literatura no México. São Paulo: Annablume.

BADIOU, A. (2009); Compendio de metapolítica. Trad. Juan Manuel Spinelli. Buenos Aires: Prometeo.

BAKHTIN, M. (1988); Questões de literatura e de estética. A teoria do romance. Trad. Aurora Fornoni Bernardini et al. São Paulo: Huicitec.

BALIBAR, E. (1996); “The nation form: History and Ideology”. In: Eley, Geoff; Suny, Ronald Grigor. (Ed.), Becoming National: A Reader. Oxford: Oxford University Press, pp. 133-151.

CORRIGAN, T. (2011); The Essay Film. From Montaigne, After Marker. Oxford: Oxford University Press.

DELEUZE, G. Y GUATTARI, F. (1995); Mil platôs. Capitalismo e esquizofrenia. Trad. de Aurélio Guerra Neto, Ana Lúcia de Oliveira, Célia Pinto Costa et al. São Paulo: Editora 34.

DUSSEL, E., MENDIETA, E. Y MENDIETA, C. (Edts.) (2009); El pensamiento filosófico latino-americano, del Caribe y "latino" (1300-2000): Historia, corrientes, temas y filósofos. México: Siglo XXI. 
FALICOV, T. L. (2000); “Argentina's Blockbuster Movies and the Politics of Culture under the Neoliberalism, 1989-1998”. In: Media, Culture and Society, 22-23, pp. 327-342.

KENWAY, J. Y FAHEY, J. (Edts.) (2009); Globalizing the Research Imagination. Londres: Routledge.

MIYOSHI, M. (2010); “A Borderless World. From Colonialism to Transnational and the Decline of Nation-State". In: Cazdyn, E. Trespasses. Selected Writtings. Masao Miyoshi, pp. 127-150, Durham/Londres.

MOREL, M. (2003); Palavra, imagem e poder: O surgimento da imprensa no Brasil do século XIX, Rio de Janeiro: DP\&A.

NAGIB, L. (2005); “Towards a Positive Definition of World Cinema”. In: Hwee, S. y Dennison, S. (Orgs.) Remapping World Cinema: Identity, Culture and Politics in Film. Londres: Wallflower Press.

(2011); World Cinema and the Ethics of Realism. Nova York/Londres: Continuum International Publishing Group.

NEGRI, A. Y HARDT, M. (2000); Empire. Cambridge/Londres: Harvard University Press.

RAMOS, F. (Org.) (2005); Teoria contemporânea do cinema. Pós-estruturalismo e filosofia analítica. São Paulo: Senac.

, (Org.) (2005); Teoria contemporânea do cinema. Documentário e narratividade ficcional. São Paulo: Senac.

RICHARD, N. (2002); Intervenções Críticas. Arte, Cultura, Gênero e Política. Belo Horizonte: Editora UFMG.

(2010); Crítica de la memoria (1990-2010), Santiago: Universidad Diego Portales.

RODRÍGUEZ, P. S. (2012); “After New Latin American Cinema”, In: Cinema Journal, vol. 51, n. 02, Winter, pp. 87-112.

SHAW, D. (2007); Contemporary Latin American Cinema. Breaking into the Global Market. Lanham, Maryland: Rowman \& Littlefield Publishers.

SONTAG, S. (1999); “The Image-World”. In: Evans, J. y Hall, S. Visual Culture: The Reader, Londres/California/Nova Déli: Sage, pp. 248-259.

SPIVAK, G. C. (2010); Pode o subalterno falar? Trad. Marcos Ferreira Feitosa et al. Belo Horizonte: UFMG.

STAM, R. (2000); Introdução à teoria do cinema, Trad. de Fernando Mascarello. São Paulo: Papirus.

WEBER, M. (1982); Ensaios de sociologia. Rio de Janeiro: Zahar Editores.

XAVIER, I. (1993); Alegorias do subdesenvolvimento. Cinema Novo, Tropicalismo, Cinema Marginal. São Paulo: Brasiliense. 
YUDICE, G. (2002); "La globalización y la nueva división internacional del trabajo cultural”, en Mónica Lacarrieu y Marcelo Álvarez (Comps.). La (indi) gestión cultural. Una cartografía de los procesos culturales contemporáneos. Buenos Aires: Ciccus. 